\title{
Nanotoxicology: a personal perspective
}

\author{
Mark M. Banaszak Holl*
}

\begin{abstract}
Nanoparticles arise from a wide variety of natural and man-made sources and have a diverse array of biological, chemical, and physical properties. The toxicity of these particles can be roughly divided into two categories: 1 ) the enhanced delivery of toxic agents 2) toxicity induced the properties of the particle itself. The use of nanoparticles to provide enhanced delivery of chemotherapeutics is presented followed by a discussion of the size-based effects of electron transfer and physical membrane disruption . ( $) 2009$ John Wiley \& Sons, Inc. WIREs Nanomed Nanobiotechnol 20091 353-359
\end{abstract}

$\mathrm{M}$ any challenges face the scientific community as it endeavors to understand the biological roles of nanoparticulate materials. ${ }^{1,2}$ First, no one traditional scientific field contains the theoretical knowledge and tools necessary to both characterize the nanomaterials and explore their interactions with biological structures. The ideas and methods of biology, biochemistry, chemistry, and physics must all be brought to bear on the problem. Second, nanomaterials arise from a wide variety of natural and man-made sources, have an incredible array of chemical and physical properties, and are difficult themselves to characterize fully. In particular, the surface composition and properties of the particles are clearly important, but often unknown, especially once introduced in the biological system. ${ }^{3,4}$ Third, biological processes as basic as endocytosis, apoptosis, and vacuole formation, all examples that are likely highly relevant to the biological activity of nanoparticles, are themselves only crudely understood for even the most common cell types. This is particularly true if one asks the question of what is occurring in these processes at the nanoscale; one scale of action likely to be disrupted by the nanoparticles. The nascent field of nanobiology, as a complement to microbiology, has yet to develop. Given these constraints arising from a combination of our training as scientists and our limited knowledge in all scientific fields regarding this problem, the development of an

\footnotetext{
*Correspondence to: mbanasza@umich.edu

Chemistry Department and Macromolecular Science and Engineering, Programs in Applied Physics and Biophysics, Graham Environmental Sustainability Institute, University of Michigan, Ann Arbor, MI, 48109-1055, USA

DOI: $10.1002 /$ wnan.027
}

understanding of nanotoxicology presents a grand challenge to the scientific community. However, given the importance of natural nanomaterials in biological structure and function, and given the rapidly influx of synthetic nanomaterials into the environment caused by human activity, it is a challenge we must embrace.

The toxic action of nanoparticle interactions with biological systems can be roughly divided into two categories. The first category includes the enhanced delivery of chemical agents known to be toxic. The second category involves the toxic effects of comparatively benign materials derived from the size-related disruption of biological structures. These two general classes of toxic behavior will be reviewed below.

\section{ENHANCED DELIVERY OF TOXIC MATERIALS}

Nanoparticles have the potential to enhance the toxicity of materials and allow them to have a greater lethal effect for a given level of exposure. This effect has the potential to be harmful or beneficial. Many of the published examples have focused on the positive aspects of this effect for biomedical applications. For example, biological macromolecules $\sim 20-160 \mathrm{KDa}$ have been shown to exhibit the enhanced permeation and retention (EPR) effect which provides a mechanism for concentration of nanoscale materials in tumors. ${ }^{5}$ This has been demonstrated for a wide variety of other nanoparticle materials including poly(ethylene glycol)-coated goldsilica nanoshells, ${ }^{6,7}$ ultrafine formulations of polymer and sol-gel materials, ${ }^{8}$ dendrimeric polymers, ${ }^{9}$ shell cross-linked micelles, ${ }^{10}$ and micelles. ${ }^{11}$ This effect 
appears to be based upon the presence of an enhanced and leaky vasculature present in the tumor combined with a reduced clearance rate for nanoparticles. Oberdörster et al. have noted that particle size has a substantial impact on where inhaled materials become located within the lung structure. ${ }^{2}$ Furthermore, transport of particles from the nasal membranes of rats to the brain has also been observed. ${ }^{12}$ It is not clear if these localization effects, and the EPR effects mentioned above, should be thought of solely as dynamic transport-based localization dependent on particle size or if the localization, and in particular the reduced clearance rates, may also be related to disruption of membranes or other biological structures in these regions.

Another method by which nanoparticles can increase the toxicity of materials is by multivalent binding effects associated with cellular receptors. Multivalency effects are well known for natural biological nanoparticles as exemplified by cell-cell, viruscell, and bacteria-cell interactions. ${ }^{13-16}$ Examples for synthetic nanoparticles made more toxic by this effect include folic acid-targeting poly(amidoamine) dendrimers. ${ }^{17,18}$ In this case, the multivalent binding leads to a local concentration of a toxic agent (methotrexate) leading to increased toxicity for the targeted cells. ${ }^{19}$ A variety of other targeted nanoparticle systems likely operating by multivalent mechanisms have also been published. These studies include HER2-targeted and disaccharide-targeted gold nanoparticles for photothermal therapy..$^{20,21}$ The above examples employ the enhanced toxicity against cancer cells for a therapeutic effect. Clearly, it would also be possible for this effect to be employed against desired healthy cells in cases where these multivalent agents would be regarded as particularly lethal toxins.

\section{SIZE-BASED PHYSICAL DISRUPTION OF BIOLOGICAL STRUCTURES}

\section{Size-based Mediation of Electron Transfer Events}

Particle-size can lead to the formation of electronic states not present for atomic or bulk phase forms of a

\section{Left panel}

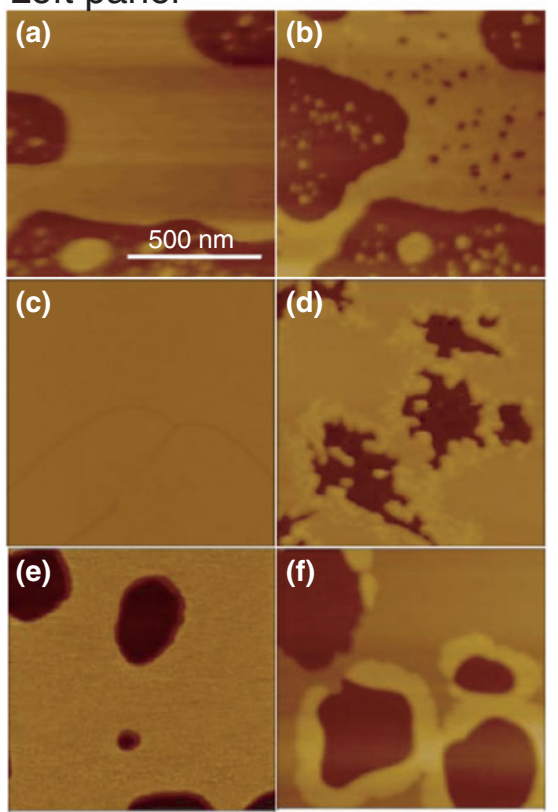

\section{Middle panel}

(a) $\mathrm{G} 7-\mathrm{NH}_{2}$

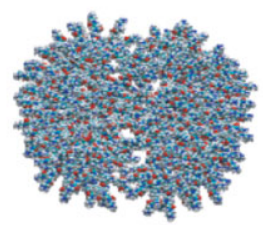

(b)

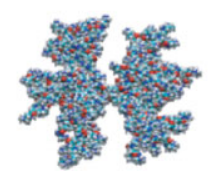

(c) $\mathrm{G} 5-\mathrm{Ac}$

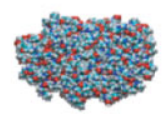

Right panel
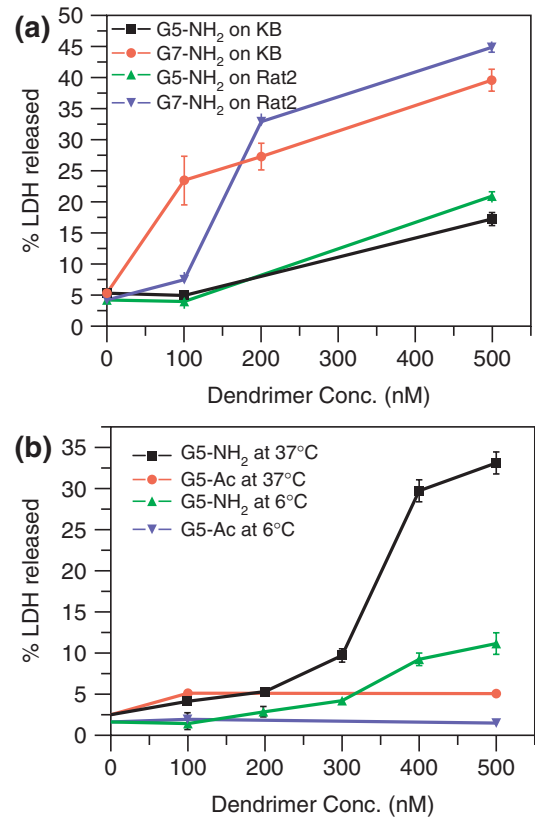

FIG URE 1 | Poly(amidoamine) (PAMAM) dendrimer interactions with biological membranes. Left panel: Atomic force microscopy (AFM) observation of dimyristoylphoshatidylcholine (DMPC) supported lipid bilayers (a), (c), and (e) before and after incubation with (b) G7-NH 2 , (d) G5- $\mathrm{NH}_{2}$, and (f) G5-Ac PAMAM dendrimers, respectively. Middle panel: Space-filling models of chemical structures of (a) G7- $\mathrm{NH}_{2}$, (b) G5-NH and (c) G5-Ac PAMAM dendrimers. Right panel: Lactate dehydrogenase (LDH) leakage as a result of cell exposure to PAMAM dendrimers. (a) Size effect of G7- $\mathrm{NH}_{2}$ and $\mathrm{G} 5-\mathrm{NH}_{2}$ on the $\mathrm{LDH}$ leakage out of $\mathrm{KB}$ and Rat2 cells after incubation at $37^{\circ} \mathrm{C}$ for $3 \mathrm{~h}$ and (b) surface group dependency on the $\mathrm{LDH}$ leakage at different temperatures. Note that larger dendrimers $\left(\mathrm{G} 7-\mathrm{NH}_{2}\right)$ induce formation of new nanoscale holes in the bilayers as seen in the AFM images and cause more amount of LDH leakage out of live cells than $\mathrm{G} 5-\mathrm{NH}_{2}$. G5- $\mathrm{NH}_{2}$ dendrimers do not cause new hole formation in the lipid bilayers but instead expand preexisting defects. In contrast, G5-Ac dendrimers do not cause hole formation, expansion of preexisting defects, or LDH leakage out of live cells. (Reprinted with permission from Ref 33. Copyright 2007 American Chemical Society) . 
material. The electronic states present in nanoscale materials have the potential to undergo electron transfer reactions ranging from the generation of reactive oxygen species (ROS) to direct interference desired in biological electron transfer reactions. This mechanism has been proposed to be an important pathway for toxicity for a variety of nanoparticles including nano- $\mathrm{C}_{60},{ }^{22}$ III-V and II-VI quantum dots (QD), ${ }^{23}$ and titania. ${ }^{24,25}$ There has been some debate in the literature regarding the origin of ROS production, particularly whether the ROS were generated by the nanoparticle itself or by cellular activity physically disrupted by the nanoparticle. ${ }^{26}$ However, recent studies continue to focus on ROS production as a significant marker of toxicity for a wide variety of nanoparticles. ${ }^{27-29}$

\section{Size-based Mediation of Membrane Disruption Events}

The second category of nanoparticles interacts with the biological system because of the interaction of the particle surface and biological structure leading to disruptive structural changes. Most commonly, disruption of the cell plasma membranes has been observed as a function of dye diffusion or cytosolic enzyme leakage assays. These approaches have been employed for a variety of materials including cell penetrating peptides ${ }^{30,31}$ and polymers (Figure 1). ${ }^{32-34}$
A combination of atomic force microscopy (AFM) on model membrane surfaces, ${ }^{35-38}$ cytosolic enzyme leakage, dye diffusion assays, and confocal microscopy; ${ }^{32,38-40}$ and electron paramagnetic resonance, transmission electron microscopy, and light scattering studies ${ }^{41}$ have been used to study the disruption mechanism of lipid bilayers and cell plasma membranes by polycationic polymers. ${ }^{33}$ These studies clearly demonstrate that polycationic nanoparticles are particularly effective in causing cell membrane permeability. In addition, they appear to continue to disrupt activities within the cell and subsequently cause additional toxicity by means of ROS production. ${ }^{26}$ On the basis of the interaction of the cationic nanoparticles with supported lipid bilayers, it appears that hole formation is one possible mechanism for the induction of permeability in the cell membranes. ${ }^{33}$ However, based upon recent coarse-grained molecular mechanics/molecular dynamics simulations of nanoparticle membrane interactions, one must also consider the formation of water channels by nanoparticles that lodge in the center of the bilayer ${ }^{42}$ as a possible permeation mechanism (Figure 2). In addition to polycationic polymers, other polycationic nanoparticles have also been observed to cause membrane permeability and to readily transport into cells. This has been demonstrated for both gold nanoparticles ${ }^{43,44}$ and $\mathrm{QD}^{45,46}$ modified with amine functional groups.
FIG URE 2 | (a) A snapshot at the beginning ( $0 \mathrm{~ns})$ of the simulation of system G5-1 (100\% acetylated). Snapshots at the end $(0.5 \mu \mathrm{s})$ of simulations of systems (b) G5-1, (c) G5-2 (50\% acetylated), (d) G5-3

(un-acetylated), (e) G5-4 (un-acetylated, $500 \mathrm{~mm} \mathrm{NaCl}$ ), (f) G5-5 (un-acetylated, low temperature), (g) G3-1 (100\% acetylated), and (h) G3-2 (un-acetylated). Black dots represent dendrimers, and blue dots represent head groups of the dipalmitoylphosphatidyl choline bilayer. The explicit water and ions are omitted for clarity. The images were created with visual molecular dynamics (VMD). (Reprinted with permission from Ref 42. Copyright 2006 Americal Chemical Society).

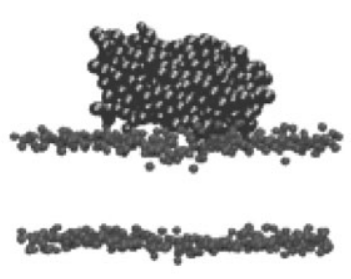

(a)

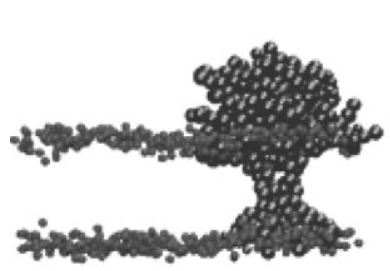

(d)

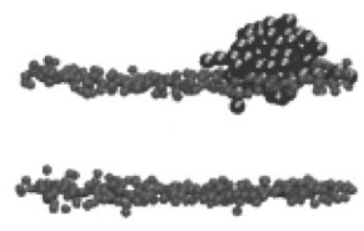

(g)

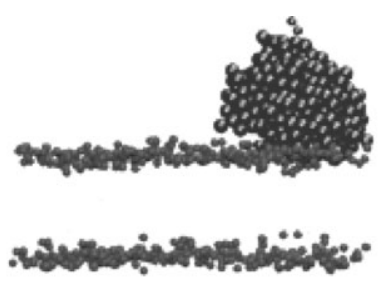

(b)

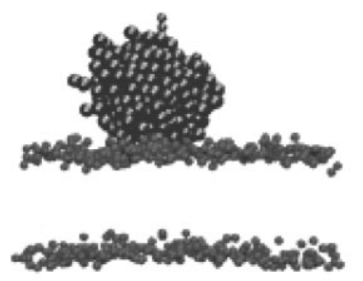

(e)

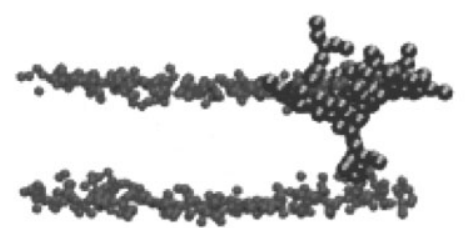

(h)

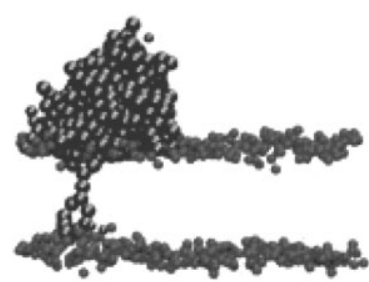

(c)

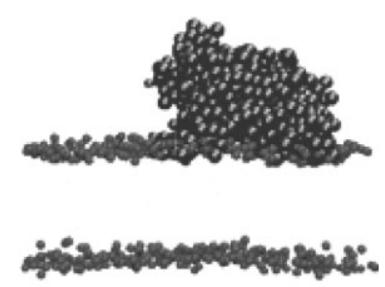

(f) 
FIGURE 3 | Confocal scanning microscopy of porcine skin treated with QD 565 for 8 h. (a-c) QD-PEG; (d-f) QD-PEG-NH2; (g-i) QD-COOH. DIC channel $(a, d, g)$ provides an unobstructed view of the skin layers. Confocal-DIC overlay with the green QD fluorescence channel $(b, e, h)$ shows QD localization within the epidermis or dermis (arrows).

Fluorescence intensity scan of the QD emission (c, f, i). QD 565 are localized in the epidermal (PEG and $\mathrm{COOH}$ coatings) or dermal (NH2 coating) layers by $8 \mathrm{~h}$. Scale bars equal $50 \mu \mathrm{m}$. (Figure revised with permission from Ref 47. Copyright 2006 Oxford Press).
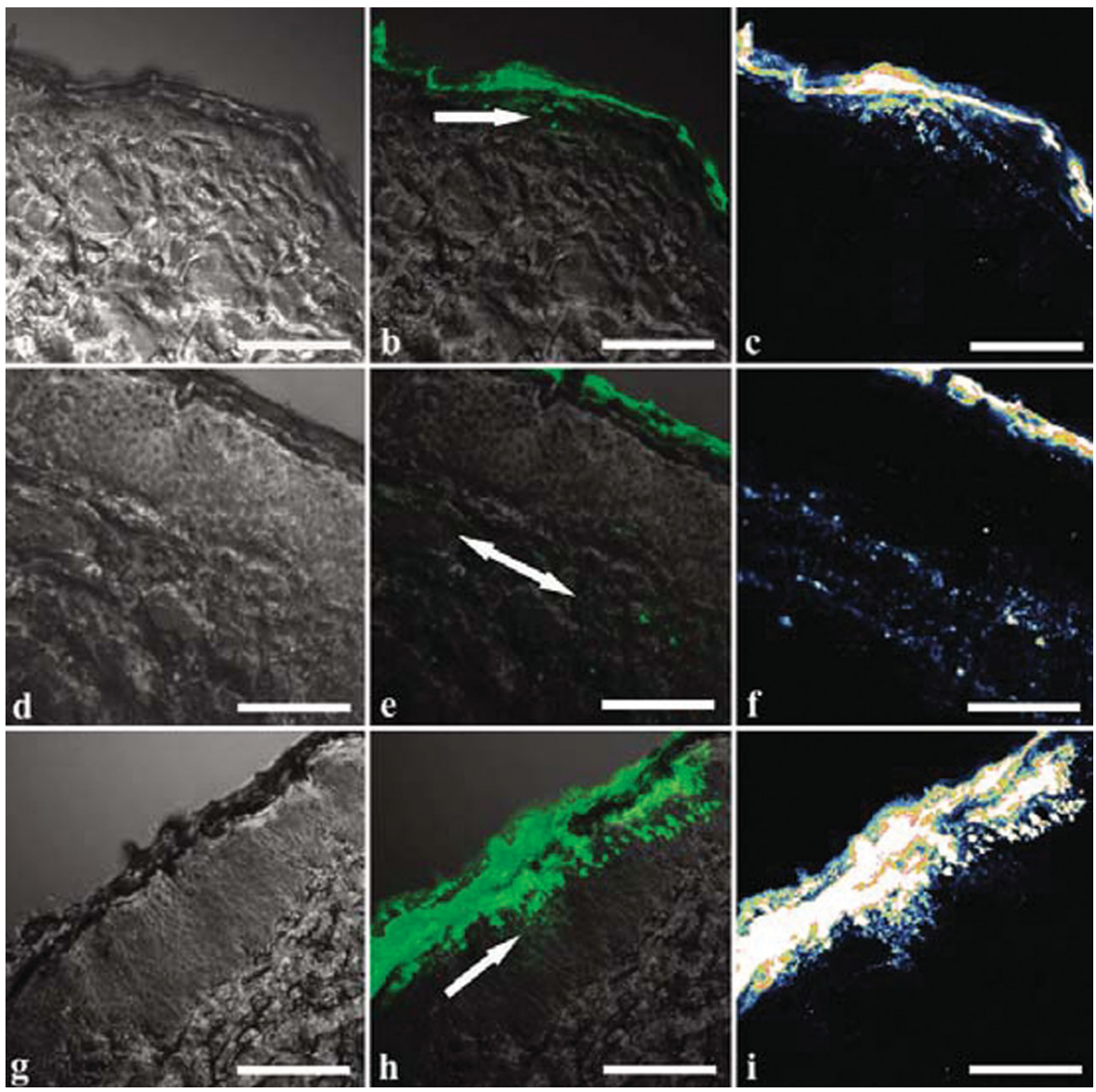

NANOPARTICLE INTERACTION WITH SKIN

The role of membrane disruption in nanoparticle localization and retention in tissue is largely unknown. Exposure of porcine skin to spherical $4.6 \mathrm{~nm}$ (QD 565) and ellipsoidal $6 \times 12 \mathrm{~nm}$ (QD 655) with poly(ethylene glycol) (neutral), carboxylic acids (anionic), and poly(ethylene glycol-amine) (cationic) coatings resulted in penetration of the stratum corneum and localization within the epidermal and dermal layers (Figure 3). ${ }^{47}$ Subsequent work with neonatal human epidermal keratinocytes (NHEK) suggests that endocytosis processes are involved in particle uptake but inhibitory effects were only about $50 \%$ indicating that other mechanisms besides macropinocytosis are active for transport of material into the cell. ${ }^{48}$ Regardless, endocytosis alone does not provide a simple explanation for how nanoparticle penetrate $50-100 \mu \mathrm{m}$ into skin. Do the particles transport through the cells or can they diffuse in between cell junctions? To what degree are biological process such as endocytosis triggered by the nanoparticles and to what extent do the particles interact with the membranes and enhance diffusion rates of materials across the membrane?

\section{THE ROLE OF NANOPARTICLE AGGREGATION}

Nanoparticles can have a complex aggregation behavior in aqueous solution and this in turn can have a substantial impact upon the particle toxicity. One of the most dramatic example of aggregation effects in aqueous systems has been observed for $\mathrm{C}_{60}$. When $\mathrm{C}_{60}$ is added to water, an aggregate of 10-1000 $\mathrm{C}_{60}$ molecules forms. It is this aggregate which has been proposed to be the active form of this nanoparticle in water. ${ }^{22}$ Similarly, fullerols have also been observed to cluster in water making $100 \mathrm{~nm}$ or larger aggregates. Aggregation effects have also been noted to play a role in the toxicity of $\mathrm{SiO}_{2}$, $\mathrm{TiO}_{2}$, and $\mathrm{ZnO}$ nanoparticles. ${ }^{49}$ Natural biological nanoparticles, including the general class of cell penetrating peptides, have long been recognized to act via clustering events that occur on the cell membrane $e^{50}$ although nanoscale and molecular level details of these events have only recently been directly elucidated. ${ }^{51,52}$ 
It is anticipated that nanoparticle aggregation in a variety of forms will play a very important role in biological activity. One aspect of aggregation in particular, interaction with proteins in serum, has recently been the subject of substantial activity.

\section{INTERACTIONS WITH NATIVE PROTEINS-DO NANOPARTICLES ACQUIRE A PROTEIN CORONA?}

The surface modification that occurs to nanoparticles upon entering tissue or blood remains largely unknown. Both the surface composition and the flexibility of the surface molecules are likely to play an important role in the types of biological species favored to bind and the strength of that binding event. Cleary, the natural nanoparticles known as enzymes are able to function in a variety of biological environments without being inactivated by the formation of a corona of surrounding protein. Similarly, the success of in vivo targeting of intravenously injected nanoparticles to the cytoplasm cancer cells ${ }^{17}$ indicates that if corona is present for these species, it is sufficiently labile to allow nanoparticle binding and endocytosis. However, for some types of nanoparticles, it is possible that strong surface binding could result in mechanisms for the aggregation of these materials and a new manner in which they would then be presented to the cell or released into the environment. Two recent reports exploring this effect for acrylamide nanoparticles did detect the presence of a protein corona. ${ }^{3,4}$
For blood, initial binding by human serum albumin followed displacement by apolipoproteins has been proposed. Clearly, these observations need further exploration for a wider variety of nanoparticles and possible protein adsorbates. The effect of the corona on nanoparticle toxicity needs to be tested.

\section{SUMMARY}

Gaining an overall understanding of nanoparticle trafficking events in biological systems is a grand challenge that must be met to understand the role of natural nanoparticles in regular biological activity and the positive and negative roles that synthetic nanoparticles will play. Given the extensive roles of membranes in biology ranging from skin to lungs to cell plasma membranes to mitochondrial membranes, interactions with nanoparticles are unavoidable and therefore must be better understood. The direct disruptive effects of nanoparticles on these biological systems, and the ability of nanoparticles to pass through membranes designed to act as barriers, create many opportunities for toxic effects to occur. The large body of data already present in the literature regarding membrane disruption $^{33}$ indicates that nanoparticles will have toxic biological effects. We must work to understand them so that the many beneficial aspects of nanotechnology give rise to a minimum number of unintended negative consequences.

\section{REFERENCES}

1. Wiesner MR, Lowry GV, Alvarez P, Dionysiou D, Biswas P. Assessing the risks of manufactured nanomaterials. Environ Sci Technol 2006, 40:4336-4345.

2. Oberdörster G, Oberdörster E, Oberdörster J. Nanotoxicology: An emerging discipline evolving from studies of ultrafine particles. Environ Health Perspect 2005, 113:823-839.

3. Cedervall T, Lynch I, Foy M, Berggad T, Donnelly SC, et al.: Detailed identification of plasma proteins adsorbed on copolymer nanoparticles. Angew Chem Int Ed 2007, 46:5754-5756.

4. Cedervall T, Lynch I, Lindman S, Berggard T, Thulin E, et al.: Understanding the nanoparticleprotein corona using methods to quantify exchange rates and affinities of proteins for nanoparticles. Proc Natl Acad Sci U S A 2007, 104:2050-2055.

5. Maeda H, Wu J, Sawa T, Matsumura Y, Hori K. Tumor vascular permeability and the EPR effect in macromolecular therapeutics: a review. J Controlled Release 2000, 65:271-284.

6. Gobin AM, Lee MH, Halas NJ, James WD, Drezek RA, et al.: Near-infrared resonant nanoshells for combined optical imaging and photothermal cancer therapy. Nano Lett 2007, 7:1929-1934.

7. Hirsch LR, Gobin AM, Lowery AR, Tam F, Drezek RA, et al.: Metal nanoshells. Ann Biomed Eng 2006, $34: 15-22$.

8. Gao D, Xu H, Philbert MA, Kopelman R. Ultrafine hydrogel nanoparticles: Synthetic approach and therapeutic application in living cells. Angew Chem Int Ed 2007, 46:2224-2227.

9. Lee CC, Gillies ER, Fox ME, Guillaudeu SJ, Frechet JMJ, et al.: A single dose of doxorubicin-functionalized bow-tie dendrimer cures mice bearing C-26 colon carcinomas. Proc Natl Acad Sci USA 2006, 103:16649-16654. 
10. Xu JQ, Sun GR, Rossin R, Hagooly A, Li ZC, et al.: Labeling of polymer nanostructures for medical imaging: Importance of cross-linking extent, spacer length, and charge density. Macromolecules 2007, 40:2971-2973.

11. Tao L, Uhrich KE. Novel amphiphilic macromolecules and their in vitro characterization as stabilized micellar drug delivery systems. J Colloid Interface Sci 2006, 298:102-110.

12. Oberdorster G, Sharp Z, Atudorei V, Elder A, Gelein R, et al.: Translocation of inhaled ultrafine particles to the brain. Inhal Toxicol 2004, 16:437-445.

13. Mammen M, Choi SK, Whitesides GM. Polyvalent interactions in biological systems: Implications for design and use of multivalent ligands and inhibitors. Angew Chem Int Ed 1998, 37:2755-2794.

14. Reuter JD, Myc A, Hayes MM, Gan ZH, Roy R, et al.: Inhibition of viral adhesion and infection by sialic-acidconjugated dendritic polymers. Bioconjug Chem 1999, $10: 271-278$.

15. Kiessling LL, Gestwicki JE, Strong LE. Synthetic multivalent ligands as probes of signal transduction. Angew Chem Int Ed 2006, 45:2348-2368.

16. Lee YC, Lee RT. Carbohydrate-Protein Interactions - Basis of Glycobiology. Acc Chem Res 1995, 28:321-327.

17. Kukowska-Latallo JF, Candido KA, Cao ZY, Nigavekar SS, Majoros IJ, et al.: Nanoparticle targeting of anticancer drug improves therapeutic response in animal model of human epithelial cancer. Cancer Res 2005, 65:5317-5324.

18. Thomas TP, Majoros IJ, Kotlyar A, KukowskaLatallo JF, Bielinska A, et al.: Targeting and inhibition of cell growth by an engineered dendritic nanodevice. $J$ Med Chem 2005, 48:3729-3735.

19. Hong S, Leroueil PR, Majoros I, Orr BG, Baker JR, et al.: The Binding Avidity of a Nanoparticle-Based Multivalent Targeted Drug Delivery Platform. Chem Biol 2007, 14:107-115.

20. Loo C, Lowery A, Halas N, West J, Drezek R. Immunotargeted nanoshells for integrated cancer imaging and therapy. Nano Lett 2005, 5:709-711.

21. Svarovsky SA, Szekely Z, Barchi JJ. Synthesis of gold nanoparticles bearing the Thomsen-Friedenreich disaccharide: a new multivalent presentation of an important tumor antigen. Tetrahedron-Asymmetry 2005, $16: 587-598$

22. Sayes CM, Gobin AM, Ausman KD, Mendez J, West JL, et al.: Nano-C-60 cytotoxicity is due to lipid peroxidation. Biomaterials 2005, 26:7587-7595.

23. Yu WW, Chang E, Drezek R, Colvin VL. Watersoluble quantum dots for biomedical applications. Biochem Biophys Res Commun 2006, 348:781-786.

24. Sayes CM, Wahi R, Kurian PA, Liu YP, West JL, et al.: Correlating nanoscale titania structure with toxicity:
A cytotoxicity and inflammatory response study with human dermal fibroblasts and human lung epithelial cells. Toxicol Sci 2006, 92:174-185.

25. Long TC, Saleh N, Tilton RD, Lowry GV, Veronesi B. Titanium dioxide (P25) produces reactive oxygen species in immortalized brain microglia (BV2): Implications for nanoparticle neurotoxicity. Environ Sci Technol 2006, 40:4346-4352.

26. Xia T, Kovochich M, Brant J, Hotze M, Sempf J, et al.: Comparison of the abilities of ambient and manufactured nanoparticles to induce cellular toxicity according to an oxidative stress paradigm. Nano Lett 2006, $6: 1794-1807$

27. Oishi M, Miyagawa N, Sakura T, Nagasaki Y. pHresponsive PEGylated nanogel containing platinum nanoparticles: Application to on-off regulation of catalytic activity for reactive oxygen species. React Funct Polym 2007, 67:662-668.

28. Lin WS, Huang YW, Zhou XD, Ma YF. In vitro toxicity of silica nanoparticles in human lung cancer cells. Toxicol Appl Pharmacol 2006, 217:252-259.

29. Hussain SM, Hess KL, Gearhart JM, Geiss KT, Schlager JJ. In vitro toxicity of nanoparticles in BRL 3A rat liver cells. Toxicol In Vitro 2005, 19:975-983.

30. Fischer R, Kohler K, Fotin-Mleczek M, Brock R. A stepwise dissection of the intracellular fate of cationic cell-penetrating peptides. J Biol Chem 2004, 279:12625-12635.

31. Rittner K, Benavente A, Bompard-Sorlet A, Heitz F, Divita G, et al.: New basic membrane-destabilizing peptides for plasmid-based gene delivery in vitro and in vivo. Mol Ther 2002, 5:104-114.

32. Fischer D, Li YX, Ahlemeyer B, Krieglstein J, Kissel T. In vitro cytotoxicity testing of polycations: influence of polymer structure on cell viability and hemolysis. Biomaterials 2003, 24:1121-1131.

33. Leroueil PR, Hong S, Mecke A, Baker JR, Orr BG, et al.: Nanoparticle Interaction with Biological Membranes: Does Nanotechnology Present a Janus Face? Acc. Acc Chem Res 2007, 40:335-342.

34. Duncan R, Izzo L. Dendrimer biocompatibility and toxicity. Adv Drug Deliv Rev 2005, 57:2215-2237.

35. Mecke A, Uppuluri S, Sassanella TJ, Lee DK, Ramamoorthy A, et al.: Direct Observation of Lipid Bilayer Disruption by Poly(amidoamine) Dendrimers. Chem Phys Lipids 2004, 132:3-14.

36. Mecke A, Lee D-K, Ramamoorthy A, Orr BG, Banaszak Holl MM. Synthetic and Natural Polycationic Polymer Nanoparticles Interact Selectively with Fluid-Phase Domains of DMPC Bilayers. Langmuir 2005, 21:8588-8590.

37. Mecke A, Majoros I, Patri AK, Baker JR, Banaszak Holl MM, et al.: Lipid Bilayer Disruption by Polycationic Polymers: The Roles of Size and Chemical Functional Group. Langmuir 2005, 21:10348-10354. 
38. Hong S, Leroueil PR, Janus EK, Peters JL, Kober MM, et al.: Interaction of polycationic polymers with supported lipid bilayers and cells: Nanoscale hole formation and enhanced membrane permeability. Bioconjug Chem 2006, 17:728-734.

39. Hong S, Bielinska AU, Mecke A, Keszler B, Beals JL, et al.: The Interaction of Polyamidoamine (PAMAM) Dendrimers with Supported Lipid Bilayers and Cells: Hole Formation and the Relation to Transport. Bioconjug Chem 2004, 15:774-782.

40. Zhang Z-Y, Smith BD. High-Generation Polycationic Dendrimers Are Unusually Effective at Disrupting Anionic Vesicles: Membrane Bending Model. Bioconjug Chem 2000, 11:805-814.

41. Ottaviani MF, Matteini P, Brustolon M, Turro NJ, Jockusch S, et al.: Characterization of starburst dendrimers and vesicle solutions and their interactions by CW- and pulsed-EPR, TEM, and dynamic light scattering. J Phys Chem B 1998, 102:6029-6039.

42. Lee H, Larson RG. Molecular Dynamics Simulations of PAMAM Dendrimer-Induced Pore Formation in DPPC Bilayers with a Coarse-Grained Model. J Phys Chem B 2006, 110:18204-18211.

43. Sandhu KK, McIntosh CM, Simard JM, Smith SW, Rotello VM. Gold nanoparticle-mediated Transfection of mammalian cells. Bioconjug Chem 2002, 13:3-6.

44. Goodman CM, McCusker CD, Yilmaz T, Rotello VM. Toxicity of gold nanoparticles functionalized with cationic and anionic side chains. Bioconjug Chem 2004, 15:897-900.

\section{FURTHER READING}

Ethical issues in nanomedicine.

Regulating nanomaterials.

A global view of regulations affecting nanomaterials.

A US view of regulatory and policy issues and guidance.
45. Smith AM, Duan HW, Rhyner MN, Ruan G, Nie SM. A systematic examination of surface coatings on the optical and chemical properties of semiconductor quantum dots. Phys Chem Chem Phys 2006, 8:3895-3903.

46. Duan HW, Nie SM. Cell-penetrating quantum dots based on multivalent and endosome-disrupting surface coatings. J Am Chem Soc 2007, 129:3333-3338.

47. Ryman-Rasmussen JP, Riviere JE, MonteiroRiviere NA. Penetration of intact skin by quantum dots with diverse physicochemical properties. Toxicol Sci 2006, 91:159-165.

48. Ryman-Rasmussen JP, Riviere JE, MonteiroRiviere NA. Variables influencing interactions of untargeted quantum dot nanoparticles with skin cells and identification of biochemical modulators. Nano Lett 2007, 7:1344-1348.

49. Adams LK, Lyon DY, Alvarez PJJ. Comparative ecotoxicity of nanoscale $\mathrm{TiO} 2, \mathrm{SiO} 2$, and $\mathrm{ZnO}$ water suspensions. Water Res 2006, 40:3527-3532.

50. Shai Y. Mode of action of membrane active antimicrobial peptides. Biopolymers 2002, 66:236-248.

51. Ramamoorthy A, Thennarasu S, Lee DK, Tan AM, Maloy L. Solid-state NMR investigation of the membrane-disrupting mechanism of antimicrobial peptides MSI-78 and MSI-594 derived from magainin 2 and melittin. Biophys J 2006, 91:206-216.

52. Mecke A, Lee DK, Ramamoorthy A, Orr BG, Banaszak Holl MM. Membrane thinning due to antimicrobial peptide binding -An AFM study of MSI-78 in DMPC bilayers. Biophys J 2005, 89:4043-4050. 